\title{
Pathways leading to early growth faltering: an investigation into the importance of mucosal damage and immunostimulation in different socio-economic groups in Nepal
}

\author{
Catherine Panter-Brick ${ }^{1}$, Peter G. Lunn ${ }^{2}$, Rebecca M. Langford ${ }^{1}$, Makhan Maharjan ${ }^{3}$ \\ and Dharma S. Manandhar ${ }^{4}$ \\ ${ }^{1}$ Department of Anthropology, Durham University, 43 Old Elvet, Durham DH1 3HN, UK \\ ${ }^{2}$ Department of Biological Anthropology, University of Cambridge, Pembroke street, Cambridge CB2 3DZ, UK \\ ${ }^{3}$ Environment and Public Health Organization (ENPHO), 110/124 Adarsa Marg-1, Thapagaon, New Baneshwor, GPO Box 4102, \\ Kathmandu, Nepal \\ ${ }^{4}$ Mother Infant Research Activities, 755 Prasuti Marg, Thapathali, GPO Box 921, Kathmandu, Nepal \\ (Received 4 October 2007 - Revised 23 May 2008 - Accepted 27 May 2008 - First published online 29 July 2008)
}

Early childhood growth retardation persists in developing countries despite decades of nutritional interventions. Adequate food is necessary, but not sufficient, to ensure normal growth where there is ubiquitous exposure to infection. Pathways associated with infection, small intestinal mucosal damage and chronic immunostimulation remain largely undemonstrated in countries other than The Gambia. We conducted a longitudinal study of one squatter and one middle-class group ( $n$ 86, 3-18 month olds) to assess these relationships in Nepal. Growth, mucosal damage index (MDI; urinary lactose:creatinine ratio adjusted for body weight), morbidity reports, and blood concentrations of albumin, $\alpha-1$-acid glycoprotein, IgG and $\mathrm{Hb}$, were recorded monthly. Growth status worsened dramatically from 6 to 18 months, with squatters more stunted (height-for-age Z-score (HAZ), $P<0.001$ ) and underweight (weight-for-age $Z$-score (WAZ), $P=0.009$ ) than middle class. IgG increased with age, was elevated in squatter children, and negatively related to WAZ $(P=0.034)$. MDI showed significant negative associations with growth performance, explaining 9 and $19 \%$ of height and weight deficits ( $\triangle \mathrm{HAZ}, P=0.004 ; \Delta \mathrm{WAZ}, P<0 \cdot 001)$. Unexpectedly, these associations were weaker in squatter children, namely in the group which showed poorer growth, elevated morbidity, greater pathogen exposure (IgG) and higher MDI $(P<0 \cdot 001)$. In Nepal, as in The Gambia, children exhibit poor growth, mucosal damage and immunostimulation. The relative impact of pathways associated with infection and undernutrition may, however, differ across socio-economic groups: in poorer children, the impact of mucosal damage and immunostimulation could be masked by nutritional constraints. This has important implications for public health interventions.

Infant growth: Intestinal permeability: Malnutrition: Immune response: Nepal: The Gambia: Public health policy

Despite decades of nutritional and health interventions, childhood growth faltering remains a feature of the life course in most developing countries ${ }^{(1)}$ : worldwide, $25 \%$ of children under 5 years are under-weight, $31 \%$ are stunted and $11 \%$ are wasted $^{(2)}$. It is during the first 2 years of life, when growth is rapid, that children seem particularly vulnerable to environmental constraints; the World Bank ${ }^{(3)}$ recently identified this period as 'the window of opportunity for addressing undernutrition'. Fig. 1 specifies the two key mechanisms that cause growth faltering. Much attention has been paid to undernutrition (pathway A), yet nutritional intervention programmes have invariably produced disappointing results, failing to raise growth performance to expected levels ${ }^{(4,5)}$. It is increasingly recognised that although an adequate supply of nutrients is clearly required, this is not sufficient to ensure normal childhood growth. Frequent and persistent infections (pathway B) resulting, for example, from increased pathogen exposure due to poor hygiene, also restrict growth ${ }^{(6-8)}$. Undernutrition and infection are closely inter-related and their synergistic effect on childhood growth has been extensively documented (see Calder \& Jackson ${ }^{(9)}$ for review).

One mechanism by which disease leads to energy deficit and growth faltering has recently been demonstrated in The Gambia. In these studies on young children $(<18$ months), over $40 \%$ of growth faltering was explained by the presence of small intestinal mucosal enteropathy associated with chronic stimulation of both local and systemic immune and inflammatory systems ${ }^{(10,11)}$. Lunn ${ }^{(11)}$ argued that pathogenic damage to the small intestine mucosa leads to (1) the loss of digestive enzymes resulting in maldigestion and malabsorption of nutrients and (2) a compromised barrier function that allows macromolecules and perhaps intact organisms to translocate into the body, leading to both local and systemic immune and inflammatory responses (Fig. 1, pathway B).

Abbreviations: AGP, $\alpha$-1-acid glycoprotein; HAZ, height-for-age Z-score; MDI, mucosal damage index; WAZ, weight-for-age Z-score; WHZ, weight-for-height Z-score.

* Corresponding author: Professor C. Panter-Brick, fax +44 (0)191 3346101, email catherine.panter-brick@durham.ac.uk 


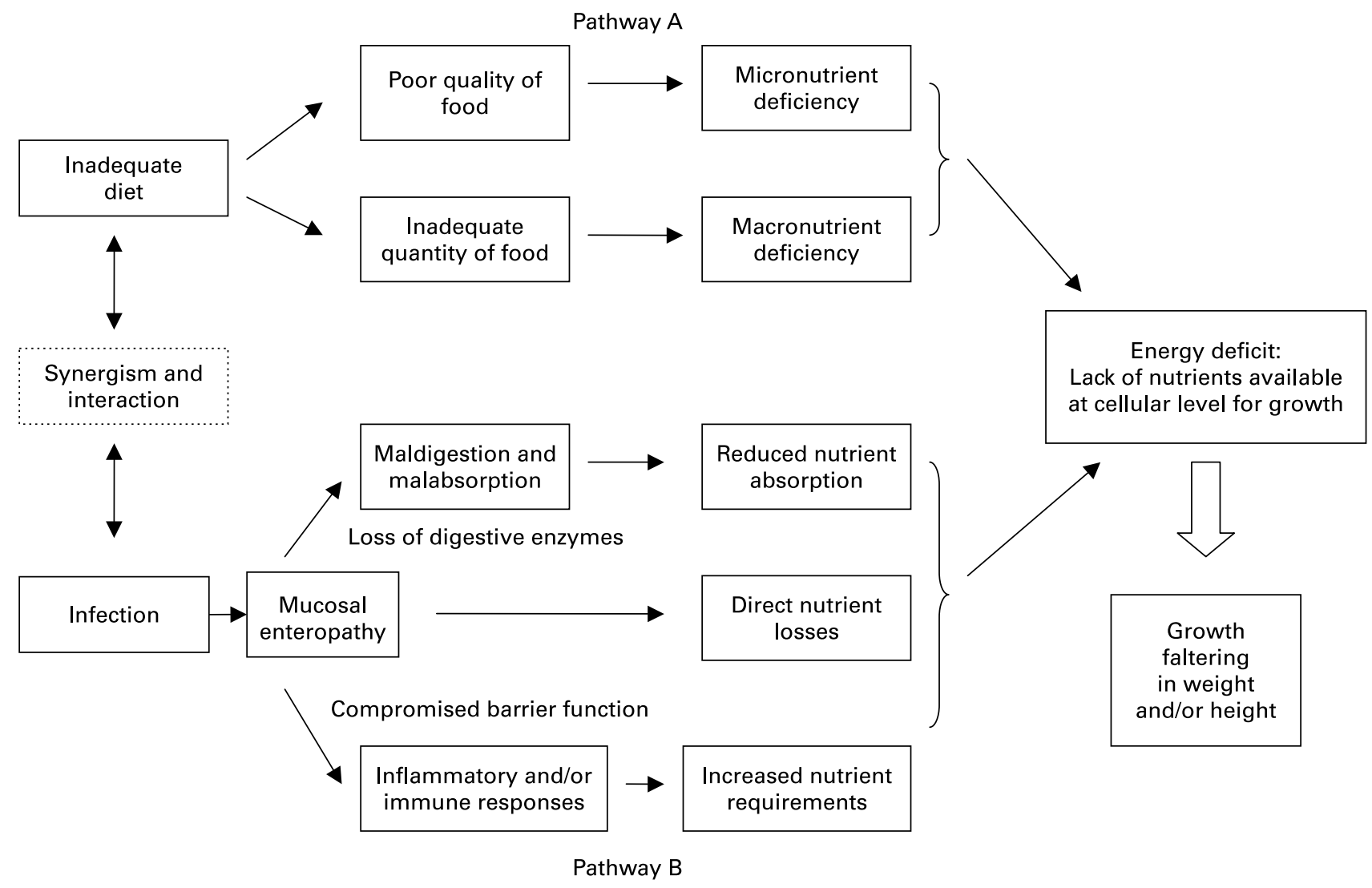

Fig. 1. A model of two pathways leading to childhood growth faltering.

An important question is whether growth faltering is associated with mucosal enteropathy and chronic immunostimulation in developing countries other than The Gambia. The present study aimed to evaluate such relationships in Nepal, where growth faltering during childhood is also very common: almost $50 \%$ of children under 5 years of age are moderately or severely stunted or underweight ${ }^{(2)}$. As in The Gambia, growth retardation coexists with extremely poor household hygiene and sanitation ${ }^{(12)}$, but differs in that there is no malaria at this altitude and breastfeeding continues for several years ${ }^{(13)}$, factors which potentially alter the associations between growth, gut damage and immune responses ${ }^{(14)}$. Because there are marked differences in growth status across rural, urban poor, and urban middle-class communities in $\mathrm{Nepal}^{(12,14-17)}$, the present study also aimed to evaluate the relative impact of gut damage and immunostimulation on growth in contrasting environments and socio-economic contexts.

\section{Participants and methods}

\section{Field sites}

The fieldwork (in 2005) coincided with a worsening of Nepal's on-going political instability, making it impossible to include a rural cohort as originally planned. The study focused on two urban cohorts, contrasting in socio-economic status, in Kathmandu, the capital of Nepal. The first was recruited from the four largest squatter settlements in Kathmandu (Ramhiti, Pathibhara, two sites in Balaju). The second cohort was recruited from lower middle-class households in a periurban area of the city (Kirtipur) where the community had previously participated in maternal-child health research ${ }^{(18)}$.

\section{Age range and sampling}

To identify the critical period of growth faltering, a baseline cross-sectional anthropometric assessment was conducted on 0-24-month-olds ( $n$ 158). This included a total sample of children in this age range living in the four squatter sites ( $n$ 79) and a random sample of age-matched middle-class children ( $n$ 79) selected from municipal household lists. This baseline assessment identified the main period of growth faltering as occurring between 6 and 18 months (data not shown).

The follow-up study therefore focused on 3-18-month-old children. This allowed younger infants (3-6 months) to enter the target age range (6-18 months) over the course of study. All squatter children aged 3-18 months ( $n$ 50) in the four study areas and a random sub-sample of age-matched middle-class children ( $n$ 40) were recruited for the longitudinal work, hereby achieving a representative sample of the squatter and middle-class population.

Measures of growth, intestinal permeability, morbidity and blood markers of immunostimulation were taken monthly, over a period of 7 months. Full datasets were obtained for forty-eight squatter and thirty-eight middle-class children ( $n$ 86), after attrition of just four children (two moved out of the area and two withdrew from the study). 


\section{Anthropometry}

Weight and length were measured following standard techniques $^{(19)}$ using portable equipment (SECA stadiometer $(0.5 \mathrm{~cm}$ precision $)$ and SECA electronic scales $(0.01 \mathrm{~kg}$ precision); Milton Keynes Scales, Leighton Buzzard, UK). All measurements were taken by the same investigator. (Duplicate measures for twenty children were taken to calculate technical errors of measurement ${ }^{(20)}$, which yielded very good coefficients of reliability, $R>0.98$.)

\section{Mucosal enteropathy}

Mucosal enteropathy was assessed using the lactose:creatinine test, a method similar to the lactulose:mannitol intestinal permeability test commonly used in previous studies ${ }^{(10,14)}$, but allows for the collection of a single, untimed urine sample. In measuring lactose rather than lactulose, this technique relies on the assumption that in children who are regularly breast-fed, the flux of lactose through the body achieves a steady state ${ }^{(21)}$. If the mucosa of the small intestine is normal, most of the lactose will be hydrolysed by intestinal lactase and the resulting monosaccharide sugars absorbed into the body; only a small amount of lactose remains intact, to be excreted in urine. In this respect, lactose behaves like its isomer lactulose, facilitating tests of mucosal integrity in a single urine sample rather than the standard $5 \mathrm{~h}$ sample required for tests of intestinal permeability.

If the mucosal surface has been reduced (e.g. by enteropathy), less lactase enzyme will be available to digest lactose. As a result, less lactose will be hydrolysed in proportion to the deficiency of lactase and degree of mucosal atrophy; more lactose will be recovered in the urine. If the mucosal barrier function is also compromised, even more lactose will translocate into the body through gaps in the intestinal walls, with urine levels rising even further. Thus increased excretion of lactose in the urine indicates either mucosal atrophy or increased leakiness of the mucosal barrier function, or a mixture of both, in the same way as the intestinal permeability ratio obtained in a $5 \mathrm{~h} \mathrm{sample}{ }^{(21)}$. Creatinine is also produced and excreted into the urine at a constant rate; in the absence of dietary creatine or creatinine, the amount excreted is dependent on body musculature ${ }^{(22)}$. Thus, in a single sample of urine, the ratio of lactose to creatinine (corrected for body musculature) will give a value dependent on mucosal status. This ratio is closely related to the lactulose:mannitol intestinal permeability ratio as a measure of mucosal status ${ }^{(23)}$.

Each month, a single untimed urine sample was collected from the children, using a sterile urine collection pad (Uricol; Ontex Healthcare, Corby, UK), which was secured inside a locally purchased nappy. Mothers were encouraged to breastfeed or give water to their children to encourage urination. The urine pad was checked every $10 \mathrm{~min}$; once wet (usually within $1 \mathrm{~h}$ ), urine was extracted using a disposable syringe. Samples $(2 \mathrm{ml})$ were preserved with bacteriostat (chlorhexidine digluconate, one drop of a $2 \mathrm{~g} / \mathrm{l}$ solution) and frozen at $-20^{\circ} \mathrm{C}$ until shipment to the UK. Urinary lactose was analysed by an enzymatic assay ${ }^{(24)}$, and creatinine by a Jaffe technique (Randox Creatinine Assay Kit; Randox, Crumlin, Co. Antrim, UK).

\section{Blood proteins}

Finger-prick samples were obtained using Hemocue lancets (Hemocue Ltd, Dronfield, UK). One drop was used to obtain an on-the-spot $\mathrm{Hb}$ value, using a haemoglobinometer (Hemocue Ltd). Up to four drops were collected on to Guthrie cards (Whatman Schleicher \& Schuell, Maidstone, UK), dried and then frozen with desiccant $\left(\right.$ at $\left.-20^{\circ} \mathrm{C}\right)$ until shipment to the UK.

Discs $(6 \mathrm{~mm})$ were punched out from the blood-spots on the Guthrie cards and plasma constituents eluted by $24 \mathrm{~h}$ incubation in $1.25 \mathrm{ml}$ phosphosaline buffer $(0.01 \mathrm{M}$-sodium phosphate, $0.5 \mathrm{M}$-sodium chloride, $\mathrm{pH} 7.2$ ) containing $1 \%$ Tween $20^{(16)}$. The eluate (approximately a 1:100 dilution of the whole blood sample) was analysed for $\mathrm{Hb}$, albumin, $\alpha-1-$ acid glycoprotein (AGP) and IgG. Hb was determined by a cyanmethaemoglobin technique (Randox Haemoglobin Assay Kit; Randox) and albumin by a turbidimetric method using reagents from DakoCytomation (Ely, UK). AGP and $\operatorname{IgG}$ were assayed by double sandwich ELISA techniques using antibodies from Insight Biotechnology (London, UK) and DakoCytomation, respectively.

Ratios between original $\mathrm{Hb}$ values (measured by the Hemocue) and $\mathrm{Hb}$ concentrations in the dried blood spots were used to correct concentrations of albumin, AGP and IgG for possible elution error. The correction factor was 1.98 , based upon recovery from the blood spots of 87.6 (SD 0.8 ) \% and the conversion factor of 2.26 obtained from our previous blood-spot data collection in Nepal ${ }^{(16)}$. It is important to appreciate that the plasma values reported here are only estimates and are quoted to allow comparison with measured plasma values in the literature. Following WHO recommended minimum values for children ${ }^{(25)}$, anaemia was defined as less than $110 \mathrm{~g} / \mathrm{l}$.

\section{Household characteristics, childcare practices and morbidity surveys}

Socio-economic and demographic data were collected from all participants using questions adapted from previous government surveys conducted in Nepal. A composite score of socio-economic status was created using data on parental levels of literacy and education, home ownership, housing type, access to water and sanitation facilities and ownership of certain valuable possessions such as radio or television.

Mothers provided morbidity reports for their child, describing all symptoms of ill-health during the $7 \mathrm{~d}$ prior to the fieldwork visit. Children's faecal samples were collected each month to assess parasitic infection load; however, following logistical difficulties and unavailability of competent laboratory technicians in Kathmandu, faecal data had to be discarded. Information on feeding practices was collected at the start of the study. Measures of dietary intakes were beyond the scope of this project, given the logistical challenges of biological sample collection in squatter settlements.

\section{Ethical approval}

Ethical approval was obtained from both the Nepal Health Research Council (Kathmandu) and Durham University Ethics and Data Protection Committee. All procedures were demonstrated to the mothers at the start of the study and 
informed consent obtained. A small gift of 120Rs (£1) was given at each measurement session. At the end of the study, mothers were offered clothing for their child and, where appropriate, children were provided with medical treatment.

\section{Statistical analyses}

Growth status was assessed from $Z$-scores for height-for-age (HAZ), weight-for-age (WAZ) and weight-for-height (WHZ), at each study point, using US National Center for Health Statistics 2000 reference data calculated with Epi Info. Growth performance was evaluated from changes in heightand weight-for-age Z-scores ( $\Delta \mathrm{HAZ}, \Delta \mathrm{WAZ}, \Delta \mathrm{WHZ})$ over the period of the study. Between-subject relationships were assessed by regression analyses using summary data (means of all monthly measurements) on each child. A mucosal damage index (MDI) was calculated by averaging monthly lactose:creatine values determined for each child over the period of study, and normalised by $\log$ transformation. Socio-economic and demographic differences between the cohorts were assessed using $\chi^{2}$, parametric and non-parametric tests, with two-tailed significance levels, using the Statistical Package for Social Sciences version 15 (SPSS, Chicago, IL, USA). For the purposes of analyses and charts, children were categorised into age bands referring to their mean age over the period of study: $6-11.9$ months, $n$ 30; $12-17.9$ months, n 26; 18-23.9 months, $n 29$.

\section{Results}

\section{Socio-economic differences}

As expected, the two groups differed greatly in socio-economic status, both in terms of the composite score $(P<0.001)$ and each constituent item. In squatter settlements, $74 \%$ of families owned their own homes, but did not have deeds to the land ${ }^{(26)}$ (Table 1). Houses were insubstantial and crowded; roofs were made of corrugated iron sheets and $51 \%$ featured no separate cooking or sleeping area. Squatters had limited access to water, using public taps, which operated only a few hours a day, and/or manually-operated rower pumps. Most families had a toilet in their own home, although $20 \%$ shared access to latrines with their neighbours or else used public toilets. Cheaper sources of cooking fuel such as firewood and kerosene were the most commonly used $(80 \%$ of families). Most families ( $90 \%$ ) did not own any item from a list of seven valuable possessions.

In the middle-class area, housing and sanitation facilities were considerably better. Houses were larger and more substantially built: $87 \%$ had a kitchen separate from the general living area and $59 \%$ had concrete or cement roofs. All families had access to a private toilet and over half (56\%) had access to piped water in their own homes, the rest relying on water from public taps nearby. Of families, $60 \%$ could afford gas or electricity as cooking fuel. Ownership of valuable possessions was recorded for $97 \%$ of families, with a median of two items.

Parental educational and occupational levels were also very different (Table 1): $43 \%$ of mothers and $14 \%$ of fathers in squatter areas were illiterate, compared to $3 \%$ for both mothers and fathers in the middle-class area. Among those who had attended school, squatters completed only primary-level education, while middle-class parents reached at least secondary level. Most squatter fathers were employed in low-paid, unskilled jobs (labourers, builders or drivers), in contrast to the skilled occupations (mechanics, shop-keepers, teachers and pharmacists) in middle-class areas (data not shown).

\section{Feeding practices}

All children enrolled in the study were breastfed throughout the period of investigation (following the custom of on-demand breastfeeding up until 2 or 3 years of age $\left.{ }^{(13)}\right)$.

Table 1. Demographic and socio-economic characteristics of households in squatter and middle-class groups*

\begin{tabular}{|c|c|c|c|c|}
\hline & Both cohorts ( $n$ 86) & Squatter ( $n$ 48) & Middle class ( $n 38$ ) & $P$ value \\
\hline \multicolumn{5}{|l|}{ Sex of child (\%) } \\
\hline Male & $44 \cdot 3$ & $46 \cdot 9$ & $41 \cdot 0$ & \multirow[t]{2}{*}{ NS } \\
\hline Female & $55 \cdot 7$ & $53 \cdot 1$ & $59 \cdot 0$ & \\
\hline \multicolumn{5}{|c|}{ Age of child (months, at start of study) } \\
\hline Mean & 11.0 & 11.4 & $9 \cdot 6$ & \multirow[t]{3}{*}{ NS } \\
\hline SD & 4.7 & $4 \cdot 7$ & 4.7 & \\
\hline Range & $3.75-17.77$ & $3.91-17 \cdot 77$ & $3.75-17.02$ & \\
\hline \multicolumn{5}{|c|}{ Socio-economic status score } \\
\hline Mean & $13 \cdot 4$ & $9 \cdot 7$ & $18 \cdot 3$ & \multirow[t]{2}{*}{$<0.0001$} \\
\hline SD & $6 \cdot 2$ & $3 \cdot 7$ & $5 \cdot 3$ & \\
\hline \multicolumn{5}{|c|}{ Father's education score $\ddagger$} \\
\hline Median & 2.5 & 2 & 3 & \multirow[t]{2}{*}{$<0.001$} \\
\hline Inter-quartiles & $1-4$ & $1-3$ & $3-5$ & \\
\hline \multicolumn{5}{|c|}{ Mother's education scoreł } \\
\hline Median & 1 & 1 & 3 & \multirow[t]{2}{*}{$<0.001$} \\
\hline Inter-quartiles & $0-3$ & $0-2$ & $1-4$ & \\
\hline \multicolumn{5}{|c|}{ Maternal BMI $\left(\mathrm{kg} / \mathrm{m}^{2}\right)$} \\
\hline Mean & $23 \cdot 2$ & $22 \cdot 1$ & $24 \cdot 6$ & \multirow[t]{2}{*}{0.001} \\
\hline SD & 3.5 & 3.3 & $3 \cdot 3$ & \\
\hline
\end{tabular}


As reported elsewhere ${ }^{(14)}$, these children have a prolonged period of mixed feeding where breastfeeding continues alongside increases in complementary foods. Complementary foods were introduced at a mean age of 5 (SD 2.23) months in both cohorts and consisted of a cereal-based porridge or small amounts of dal bhaat (the traditional Nepali staple of rice and lentils). Children of this age range receive only very small amounts of meat which would contribute to urinary creatinine.

\section{Morbidity}

Morbidity reports were collected every month; questionnaires were complete for all monthly interviews for 95 and $96 \%$ of squatter and middle-class children, respectively. Reported morbidity was higher for the poorer children (Fig. 2): sickness in the previous $7 \mathrm{~d}$ was reported for $38 \%$ of the study period among squatters relative to $25 \%$ of the time among the middle class. Reports of diarrhoea and fever were more frequent among the former, coughs and colds among the latter.

\section{Growth}

The deterioration in anthropometric status during the first 2 years of life is clearly illustrated in Fig. $3(\mathrm{a}-\mathrm{c})$. Two points are evident from these data. Firstly, both groups experienced marked faltering in height and weight. Thus middle-class children showed a slow, progressive deterioration in growth status throughout the age range; squatter children showed a marked deterioration for HAZ and WAZ at 12-18 months relative to infancy, but stabilised beyond this age. WHZ also fell progressively with age in both groups. Secondly, as expected, middle-class children were taller and heavier than their squatter counterparts (HAZ, $P<0.001$ and WAZ, $P=0.009$ overall for all children, at end-point of study). However, statistically significant differences between groups only emerged for HAZ after 12 months of age (12-18 months, $P<0.01$; 18-24 months, $P<0 \cdot 026$ ).

Growth performance over the 7 months of study did not differ between cohorts: $\triangle \mathrm{HAZ}-0.064$ (SD 0.013) and 0.040 (SD 0.014) for squatter and middle class, respectively; $\Delta \mathrm{WAZ},-0.082$ (SD 0.015) and -0.070 (SD 0.017) for squatter and middle class, respectively.

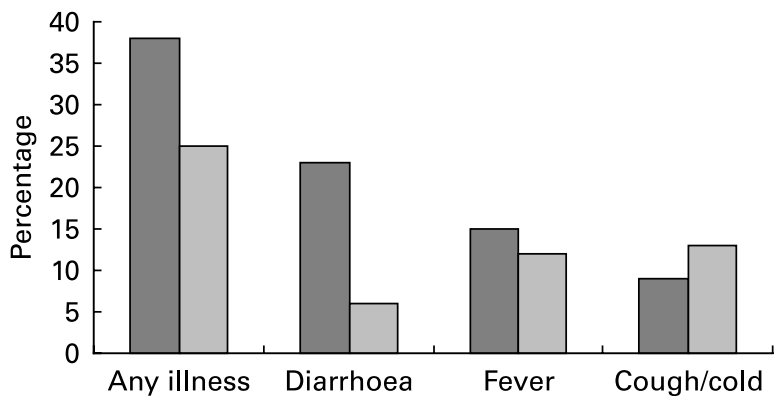

Fig. 2. Reported morbidity levels ( $7 \mathrm{~d}$ recall) for squatter children ( $\square, n$ 48) and middle-class children ( $\square, n$ 38). Percentages of reported morbidity each month were averaged across the period of study.
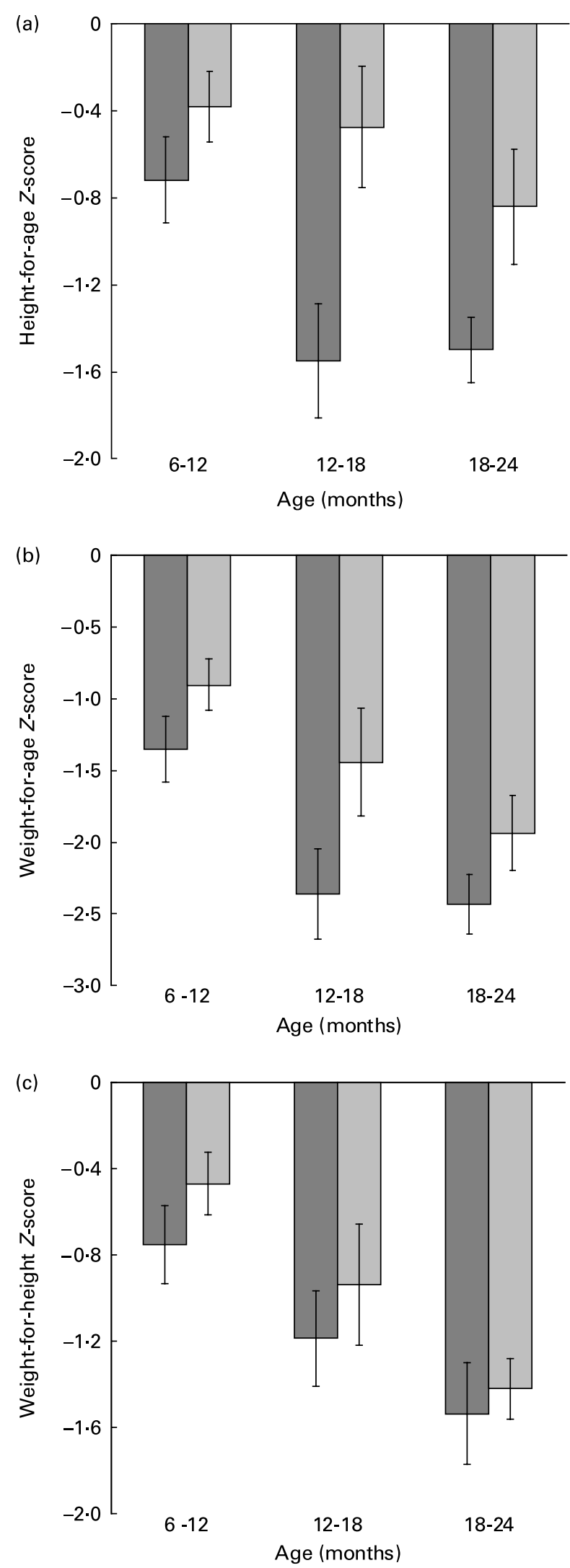

Fig. 3. Growth status for squatter $(\square)$ and middle-class $(\square)$ children $(n 86)$ in the longitudinal study as Z-scores for height-for-age (a), weight-for-age (b), weight-for-height (c). Values are means with their standard errors depicted by vertical bars. 

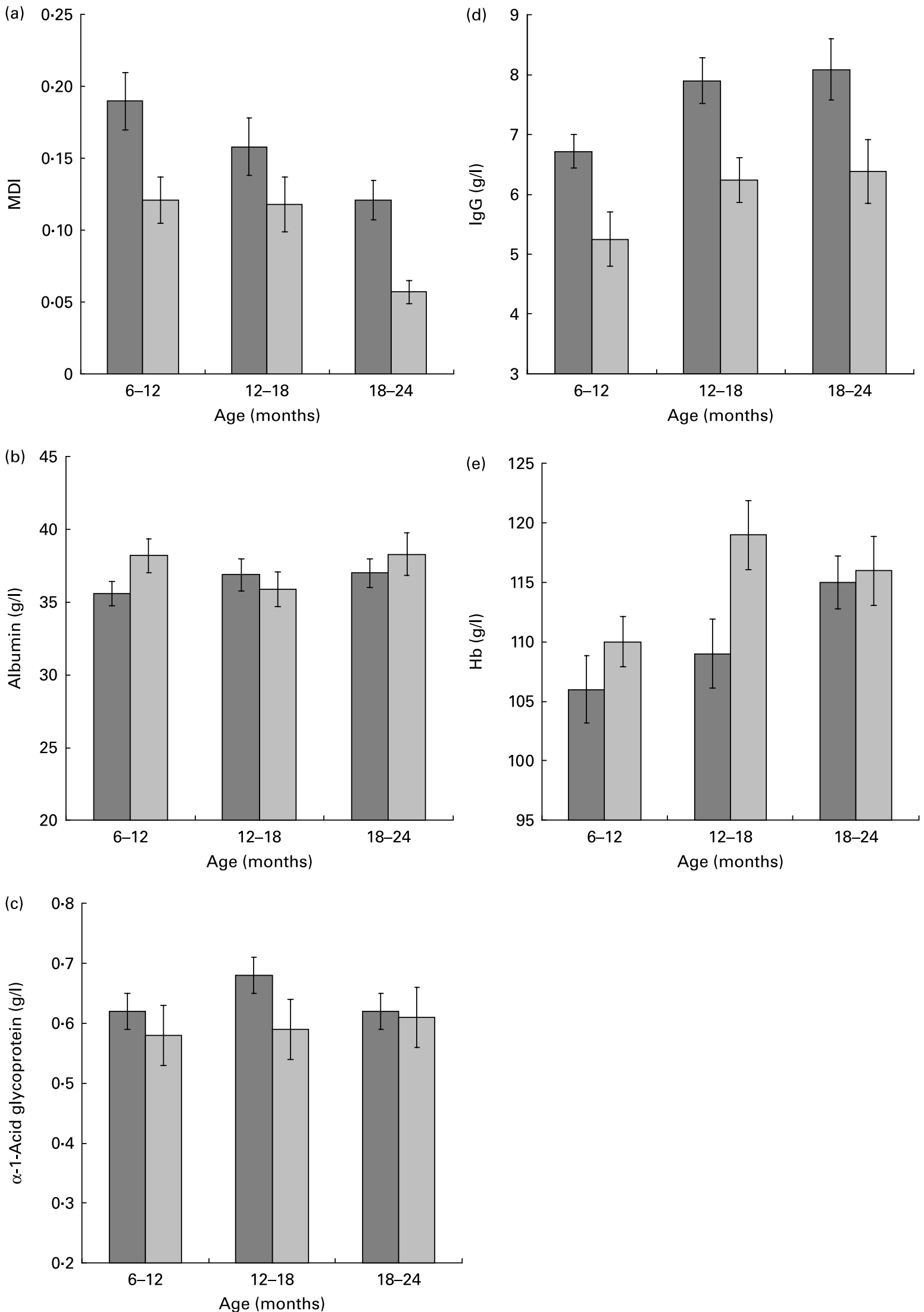

Fig. 4. Comparison of mucosal damage index (MDI) and plasma protein values for squatter ( $\square$ ) and middle-class ( $\square$ ) children ( $n$ 86) for different age bands. (a), MDI; (b), albumin; (c), $\alpha$-1-acid glycoprotein; (d), Hb; (e), IgG. Values are means with their standard errors depicted by vertical bars. 


\section{Mucosal damage and blood proteins}

Fig. 4 shows both cohort differences and age-related changes in MDI and blood protein values. Overall, MDI was higher in squatter than in middle-class children: for all ages, geometric means were 0.14 (95\% CI $0 \cdot 12,0 \cdot 16)$ and 0.08 (95\% CI 0.07, $0 \cdot 10$ ), respectively (data not tabulated; $P<0 \cdot 001$ ). For both cohorts, there was a fall in MDI values, i.e. an improvement in mucosal status, with increasing age (Fig. 4 (a), $P<0.001$ ). Differences between groups were statistically significant at 6-12 months $(P=0 \cdot 007)$ and $18-24$ months $(P=0 \cdot 002)$, but not $12-18$ months.

Plasma albumin and AGP concentrations (Fig. 4 (b, c)) did not differ between groups and neither changed consistently with age. IgG concentrations (Fig. 4 (d)), however, were higher in the squatter children (all ages $P<0.001$; and in the three age bands $P=0.01, P=0.005, P=0.03$, respectively). IgG also increased with age in both groups $(P=0.002) \mathrm{Hb}$ concentrations (Fig. 4 (e)) were elevated in the middle class relative to squatters $(P=0.03)$, increasing with age in the latter $(P=0.007)$ but not the former. $\mathrm{Hb}$ was also negatively related to MDI (overall, $r^{2} 0 \cdot 18 ; P<0.001$; in middle class, $r^{2} 0 \cdot 13$, $P=0 \cdot 03$; in squatter, $r^{2} 0 \cdot 16, P=0 \cdot 005$; data not shown).

\section{Associations with growth}

Regarding growth status, higher MDI values were strongly associated with lower HAZ, WAZ and WHZ (Table 2). When cohorts were analysed separately, MDI associations

Table 2. Associations between mucosal damage index and growth status/performance over the period of study*

\begin{tabular}{|c|c|c|c|c|}
\hline & $n$ & $r^{2}$ & $\beta$ coefficient & $P$ value $\dagger$ \\
\hline \multicolumn{5}{|l|}{ Growth status } \\
\hline \multicolumn{5}{|l|}{ HAZ } \\
\hline All children & 86 & 0.12 & -0.38 & $<0.001$ \\
\hline Squatter & 48 & 0.00 & -0.09 & NS \\
\hline Middle class & 38 & 0.16 & -0.49 & 0.009 \\
\hline \multicolumn{5}{|l|}{ WAZ } \\
\hline All children & 86 & 0.20 & -0.49 & $<0.001$ \\
\hline Squatter & 48 & 0.13 & -0.40 & 0.004 \\
\hline Middle class & 38 & 0.20 & -0.53 & 0.002 \\
\hline \multicolumn{5}{|l|}{ WHZ } \\
\hline All children & 86 & 0.16 & -0.44 & $<0.001$ \\
\hline Squatter & 48 & 0.21 & -0.51 & $<0.001$ \\
\hline Middle class & 38 & 0.11 & -0.40 & 0.02 \\
\hline \multicolumn{5}{|c|}{ Growth performance } \\
\hline \multicolumn{5}{|c|}{$\Delta \mathrm{HAZ}$} \\
\hline All children & 86 & 0.09 & -0.31 & 0.004 \\
\hline Squatter & 48 & 0.01 & -0.11 & NS \\
\hline Middle class & 38 & 0.22 & -0.47 & 0.003 \\
\hline \multicolumn{5}{|l|}{$\triangle W A Z$} \\
\hline All children & 86 & 0.19 & -0.44 & $<0.001$ \\
\hline Squatter & 48 & 0.14 & -0.38 & 0.007 \\
\hline Middle class & 38 & 0.29 & -0.54 & $<0.001$ \\
\hline \multicolumn{5}{|l|}{$\Delta \mathrm{WHZ}$} \\
\hline All children & 86 & 0.02 & -0.14 & NS \\
\hline Squatter & 48 & 0.05 & -0.22 & NS \\
\hline Middle class & 38 & 0.00 & -0.04 & NS \\
\hline
\end{tabular}

HAZ, height-for-age Z-score; WAZ, weight-for-age Z-score; WHZ, weight-for-height $Z$-score.

${ }^{*}$ For details of procedures, see Participants and methods.

† Group differences by multiple regressions correcting for age. with WAZ and WHZ remained significant (stronger in middle class for WAZ, but stronger in squatters for WHZ). However for HAZ, associations were significant only in the middle-class group.

Regarding growth performance, $\Delta \mathrm{HAZ}$ and $\Delta \mathrm{WAZ}$ were also significantly related to MDI (Fig. $5(\mathrm{a}, \mathrm{b})$ ); this was not the case for $\Delta$ WHZ (Table 2). Despite the fact that squatter children exhibit higher MDI values, relationships with $\Delta$ WAZ ( $\beta$-coefficients) were weaker than those observed in middle-class children; for $\Delta \mathrm{HAZ}$, relationships did not reach statistical significance. In all cases, the higher the MDI, the poorer the growth performance.

Plasma IgG concentrations were negatively related to WAZ $(P=0.034)$, but no relationships were observed with other measures of growth status (HAZ, WHZ), or growth performance $(\Delta \mathrm{HAZ}, \Delta \mathrm{WAZ}, \Delta \mathrm{WHZ})$, over the period of the study. Likewise, no significant correlations between plasma AGP and any of the growth variables were detected. In all but one round of study, AGP was elevated in children for whom mothers reported morbidity during the $7 \mathrm{~d}$ preceding blood sampling (data not shown). In contrast, IgG concentrations were not associated with reported morbidity.
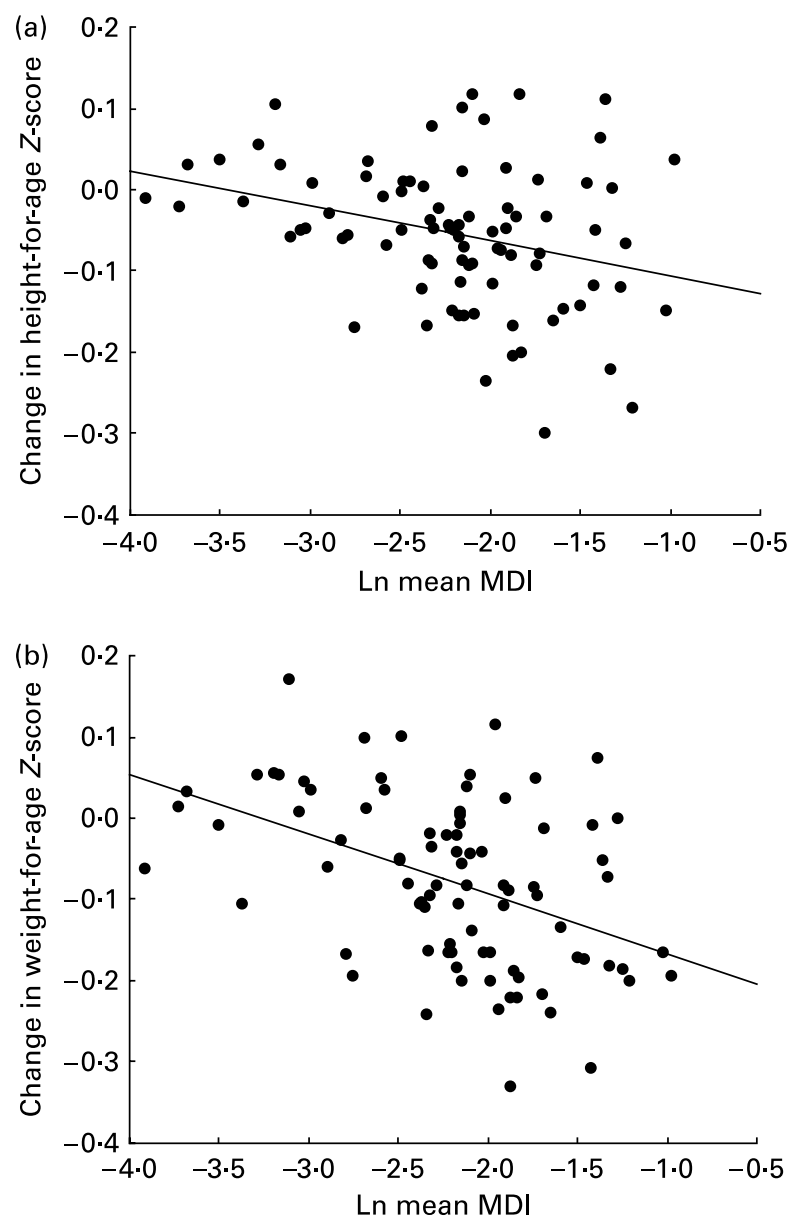

Fig. 5. Relationships between mucosal damage index (MDI) and growth performance over the period of study. Each point represents the mean MDI and the change in $Z$-score for an individual child $(n 86)$. (a), Change in height-forage $Z$-scores $(\triangle \mathrm{HAZ}): r^{2} 0.09, P=0.004$. (b), Change in weight-for-age $Z$-scores (DWAZ): $r^{2} 0.19, P<0.001$. 


\section{Discussion}

A primary aim of the present study was to establish whether mucosal enteropathy might contribute to the growth faltering observed in Nepali children. We report significant associations between the severity of small intestinal mucosal damage (as measured by lactose:creatinine, corrected for body weight) and growth measures in breastfed children under 2 years of age. A higher MDI, indicative of greater mucosal disruption, was associated in multiple regressions with both poorer growth status $(P<0.001$ for HAZ, WAZ and WHZ) and poorer growth performance during the period of the study $(P=0.004$ for $\triangle \mathrm{HAZ}, P<0.001$ for $\Delta \mathrm{WAZ}$; Table 2$)$. Considering both cohorts together, the MDI explained $9 \%$ of the deficit in height and $19 \%$ of the deficit in weight gain.

A secondary aim was to establish the relative importance of these associations across different environmental and socioeconomic contexts. Unexpectedly, the relative impact of MDI on growth performance was stronger in the middle-class cohort, despite the fact that, in absolute terms, the squatters exhibited poorer growth status and more severe mucosal damage. Among middle-class children, MDI accounted for $22 \%$ of faltering in height growth $(\triangle \mathrm{HAZ})$, whereas among squatters it had no significant impact. Again, among middleclass children, MDI accounted for $29 \%$ of deterioration in weight gain ( $\triangle \mathrm{WAZ}$ ), relative to only $14 \%$ among squatters. Relationships between MDI and both $\triangle \mathrm{HAZ}$ and $\Delta \mathrm{WAZ}$ ( $\beta$-coefficients) were notably stronger in the middle class; this was also true for the cross-sectional measures of growth status (HAZ and WAZ), but not for $\triangle \mathrm{WHZ}$ nor for WHZ (Table 2).

If we consider infection as a primary cause of growth faltering (Fig. 1, pathway B), such results are unexpected. Relative to the middle class, squatter families lived in much poorer areas, with higher levels of overcrowding, poor hygiene and sanitation facilities, resulting in a more pathogenic environment; moreover, they were worse off in terms of socio-economic status, material wealth, occupation and literacy. As we have shown, squatter children exhibited poorer growth (HAZ, $P<0.001$; WAZ, $P=0.009$ ), higher levels of mucosal damage $(P<0 \cdot 001)$ and higher plasma IgG concentrations $(P<0 \cdot 001)$, a useful indicator of longterm exposure to infection, relative to middle-class children. They also had elevated morbidity, in particular diarrhoea and fevers. Thus they showed greater exposure to pathogens, poorer mucosal integrity and increased immunostimulation; yet the associations between mucosal damage and growth were less pronounced than those observed for the better-off, middle-class children. Why might this be the case?

The present data suggest that growth amongst squatter children is being constrained by several powerful factors. Given significant logistic challenges in Kathmandu, we focused the study on evaluating the impact of infection on growth (pathway B); we did not include a quantitative evaluation of dietary intakes (pathway A). Our experience of the field, which includes participant observation over 7 months of study, suggests that dietary intake (quality and/or quantity) is likely to be a greater problem in squatter settlements than in middle-class areas. Evidence of greater nutritional constraints in the squatter areas is shown from data on maternal BMI: $10 \%$ of mothers were underweight $\left(\mathrm{BMI}<18.5 \mathrm{~kg} / \mathrm{m}^{2}\right)$ in squatter areas, compared to just $3 \%$ in middle-class areas.
It is fair to say that squatter children faced greater constraints with respect to both pathway A (undernutrition) and pathway B (infection), compared to middle-class children. It may be that pathway A placed the greatest constraint on growth, and that this masked the relative impact of MDI for the squatter children. In the middle-class group, where there may be fewer dietary constraints, the impact of MDI was more pronounced.

We suspect that if one were to implement a nutritional intervention in squatter areas, it would (like in many other trials ${ }^{(4,5)}$ ) fail to improve growth performance in any lasting way; alleviating the one problem (undernutrition) would simply unmask the impact of a second (mucosal damage and infection). This would have important implications for public health policy: the implementation of nutritional interventions, without addressing basic issues of hygiene, sanitation and pathogen exposure, is unlikely to have much impact on the growth of the poorest children.

The results of the present study are based on a novel index of mucosal integrity, the lactose:creatinine ratio, developed specifically for use with breastfed children. It has a number of advantages over the commonly used lactulose:mannitol intestinal permeability test to assess small bowel mucosal integrity ${ }^{(11,27)}$, which requires dosing infants with the lactulose:mannitol sugar solution and a $5 \mathrm{~h}$ urine collection period, greatly limiting its acceptability to mothers and usage in the field. By contrast, the lactose:creatinine test is extremely non-invasive, proceeding without dosing and requiring only a single 'spot' urine sample collected onto absorbent cotton wool. It is less accurate than the intestinal permeability test, given that baseline assumptions (a standard intake of breastmilk for children across all ages, and an insignificant supply of dietary creatinine) may not always be met. However, departures from these assumptions will affect the lactose:creatinine ratio only to a small extent, relative to the very large changes in lactose uptake by the small intestine. For example, the geometric mean for lactose:creatinine (adjusted for body weight) in this study was 0.10 (2 SD 0.02-0.56; more than a 20 -fold range); by contrast a large $( \pm 25 \%)$ variation in milk ingestion would lead to much smaller ratio changes $( \pm 25 \%)$. Variation in creatinine excretion due to periods of increased catabolism or muscle wasting would similarly affect the ratio by relatively small amounts ${ }^{(23)}$. In cases of severe wasting, it may be necessary to correct for body musculature more accurately than by using body weight, but as children in the present study were not wasted (Fig. 3 (c)), the use of body weight does not introduce a large error. While dietary creatinine would raise urinary creatinine concentration, it is unlikely that these Nepali children received enough meat or meat products to affect the validity of the results. A field study designed specifically to validate the lactose:creatinine test suggests it is a useful index of small bowel mucosal damage, given its close correlations with lactulose:mannitol intestinal permeability results $^{(21)}$.

Table 3 summarises the comparison between the present data from Nepal and data from The Gambia (unpublished results from Campbell et al. ${ }^{(10)}$ ), albeit for different urban (Nepal)/rural (The Gambia) groups and small sub-samples (restricted to age-matched children). Relative to The Gambia, the middle class in Nepal show better height- and weight-for-age $(P<0.001$ and $P<0.05$, respectively), lower 
Table 3. A comparison of anthropometric data, plasma protein concentrations and mucosal damage index (MDI) of age-matched children in Nepal and The Gambia*

(Mean values and standard deviations)

\begin{tabular}{|c|c|c|c|c|c|c|c|c|}
\hline & \multicolumn{2}{|c|}{ Nepal } & \multicolumn{2}{|c|}{ Nepal } & \multicolumn{2}{|c|}{ The Gambia } & \multirow[b]{3}{*}{$\begin{array}{c}P \text { value for Nepal squatter } \\
v . \text { The Gambia§ }\end{array}$} & \multirow[b]{3}{*}{$\begin{array}{l}P \text { value for Nepal middle } \\
\text { class } v \text {. The Gambias }\end{array}$} \\
\hline & \multicolumn{2}{|c|}{$\begin{array}{c}\text { Squatter } \\
\text { sub-sample }(n \text { 15) } \dagger\end{array}$} & \multicolumn{2}{|c|}{$\begin{array}{c}\text { Middle class } \\
\text { sub-sample }(n 12) \dagger\end{array}$} & \multicolumn{2}{|c|}{$\begin{array}{c}\text { All } \\
(n 50) \ddagger\end{array}$} & & \\
\hline & Mean & SD & Mean & SD & Mean & SD & & \\
\hline \multicolumn{9}{|l|}{ Anthropometry } \\
\hline Age (months) & 11.2 & $2 \cdot 1$ & 11.4 & 1.9 & 11.0 & $2 \cdot 3$ & NS & NS \\
\hline Height $(\mathrm{cm})$ & $70 \cdot 3$ & $2 \cdot 6$ & 73.0 & 3.5 & 69.6 & $3 \cdot 2$ & NS & $<0.01$ \\
\hline Weight (kg) & 8.00 & 0.92 & 8.49 & 1.06 & 7.62 & 0.99 & NS & $<0.05$ \\
\hline $\mathrm{HAZ}$ & -1.15 & $1 \cdot 19$ & -0.25 & 0.99 & -1.56 & 1.01 & NS & $<0.001$ \\
\hline WAZ & -1.77 & 1.36 & -1.21 & 1.02 & $-2 \cdot 12$ & $1 \cdot 19$ & NS & $<0.05$ \\
\hline \multicolumn{9}{|l|}{ Plasma proteins } \\
\hline Albumin (g/l) & $40 \cdot 0$ & $6 \cdot 7$ & $35 \cdot 8$ & $9 \cdot 6$ & $35 \cdot 6$ & 3.73 & $<0.05$ & NS \\
\hline $\lg G(g / l)$ & 8.67 & 2.78 & $6 \cdot 81$ & 1.67 & 9.54 & $2 \cdot 56$ & NS & $<0.01$ \\
\hline MDIף & 0.15 & $0.12,0.19$ & 0.12 & $0.08,0.17$ & 0.22 & $0.19,0.25$ & $<0.05$ & $<0.001$ \\
\hline
\end{tabular}

HAZ, height-for-age $Z$-score; WAZ, weight-for-age $Z$-score.

${ }^{*}$ For details of procedures, see Participants and methods.

† Restricted to the age-range available for The Gambia.

‡Unpublished results from Campbell et al. ${ }^{(10)}$.

$\S$ Group differences by ANOVA with Bonferroni correction.

I Values are geometric means and $95 \% \mathrm{Cl}$.

plasma IgG concentrations $(P<0 \cdot 01)$ and less severe mucosal damage $(P<0.001)$. The Nepali squatter children are similar to the Gambians in terms of height, weight and IgG levels; however, their MDI is lower $(P<0 \cdot 05)$, indicating less mucosal damage, with a weaker relationship with growth. In Nepal (Table 2), MDI values accounted for 9 and $19 \%$ of growth deficits in height and weight, respectively (for squatters, $1 \%$ of $\triangle \mathrm{HAZ}$ and $14 \%$ of $\triangle \mathrm{WAZ}$; for middle class, 22 and $29 \%$, respectively). This compares to 43 and $40 \%$ of height and weight deficits reported in The Gambia ${ }^{(11)}$.

The data indicate differences in the relative importance of pathways A and B underlying growth faltering in young children. For Gambian infants, it may be that infection, not diet, is the greatest stressor for growth, perhaps as a consequence of their early introduction of complementary foods. In Nepal, while infection is clearly a problem, it may be that undernutrition is the greater constraint on growth faltering, at least among squatters. The present study highlights the need for further research into the relative impact of infection and nutrition across social ecologies, at different key ages of life history and child development.

\section{Acknowledgements}

There are no conflicts of interest, either financial or contractual. The fieldwork for this research was funded by a grant (to C. P.-B.) from the Wenner Gren Foundation (grant no. 7228). All authors have read and approved the manuscript. C. P.-B. designed the study and set up the fieldwork in Nepal; R. M. L. managed the project, over-seeing all data collection; M. M. and D. S. M. facilitated local ethical approval and fieldwork procedures; P. G. L. performed laboratory analyses; R. M. L., C. P.-B. and P. G. L. undertook statistical analyses and manuscript preparation.

\section{References}

1. Shrimpton R, Victora CG, de Onis M, Lima RC, Blössner M \& Clugston G (2001) Worldwide timing of growth faltering: implications for nutritional interventions. Pediatrics 107, e75.

2. UNICEF (2008) Global Database on Child Malnutrition 2008, http://www.childinfo.org (accessed 25 February 2008).

3. World Bank (2006) Repositioning Nutrition as Central to Development. Washington, DC: The World Bank.

4. Prentice A (1993) Nutrient requirements for growth, pregnancy and lactation: the Keneba experience. S Afr J Clin Nutr 6, 33-38.

5. Bhutta ZA, Ahmed T, Black RE, et al. (2008) What works? Interventions for maternal and child undernutrition and survival. Lancet 371, 417-440.

6. Mata L, Kromal R, Urrutia J \& Garcia B (1977) Effect of infection on food intake and the nutritional status: perspectives as viewed from the village. Am J Clin Nutr 30, 1215-1227.

7. Solomons NW, Mazariegos M, Brown KH \& Klasing $\mathrm{K}$ (1993) The underprivileged, developing country child: environmental contamination and growth failure revisited. Nutr Rev 51, 327-332.

8. Solomons NW (2003) Environmental contamination and chronic inflammation influence human growth potential. J Nutr 133, $1237-1238$.

9. Calder P \& Jackson A (2000) Undernutrition, infection and immune function. Nutr Rev 13, 3-29.

10. Campbell DI, Elia M \& Lunn PG (2003) Growth faltering in rural Gambian infants is associated with impaired small intestinal barrier function, leading to endotoxemia and systemic inflammation. J Nutr 133, 1332-1338.

11. Lunn PG (2000) The impact of infection and nutrition on gut function and growth in childhood. Proc Nutr Soc 59, 147-154.

12. Moffat T (2003) Diarrhea, respiratory infections, protozoan gastrointestinal parasites, and child growth in Kathmandu, Nepal. Am J Phys Anthropol 122, 85-87.

13. Moffat T (2001) A biocultural investigation of the weanling's dilemma in Kathmandu, Nepal: do universal recommendations for weaning practices makes sense? J Biosoc Sci 33, 321-338. 
14. Goto R, Panter-Brick C, Nothrop-Clewes CA, Manahdhar R \& Tuldadhar NR (2002) Poor intestinal permeability in mildly stunted Nepali children: associations with weaning practices and Giardia lamblia infection. Br J Nutr 88, 141-149.

15. Costello A (1989) Growth velocity and stunting in rural Nepal. Arch Dis Child 64, 1478-1482.

16. Panter-Brick C, Lunn PG, Baker R \& Todd A (2001) Elevated acute-phase proteins in stunted Nepali children reporting low morbidity: different rural and urban profiles. Br J Nutr 85, 125-131.

17. Worthman CM \& Panter-Brick C (2008) Homeless street children in Nepal: use of allostatic load to assess the burden of childhood adversity. Dev Psychopathol 20, 233-255.

18. Shrestha PL, Osrin D, Manandhar DS \& Costello AM de L (2000) Mothers' recall of infant size at birth in the evaluation of low birth weight prevalence: an assessment from Nepal. J Nep Med Assoc 39, 210-217.

19. Lohman TG, Roche AF \& Martorell R (1988) Anthropometric Standardisation Reference Manual. Champaign, IL: Human Kinetics Books.

20. Ulijaszek SJ \& Kerr DA (1999) Anthropometric measurement error and the assessment of nutritional status. Br J Nutr 82, 165-177.
21. Northrop-Clewes CA, Lunn PG \& Downes RM (1997) Lactose maldigestion in breast-feeding Gambian infants. J Pediatr Gastroenterol Nutr 24, 257-263.

22. Matos V, van Melle G, Boulat O, Markert M, Bachmann C \& Guignard JP (1997) Urinary phosphate/creatinine, calcium/creatinine and magnesium/creatinine ratios in a healthy pediatric population. J Pediatr 131, 252-257.

23. Beasley BA \& Lunn PG (2003) Lactose and creatinine excretion as an alternative to the lactulose/mannitol intestinal permeability. Ann Hum Biol 31, 605.

24. Northrop CA, Lunn PG \& Behrens RH (1990) Automated enzymatic assays for the determination of intestinal permeability probes in urine. 1. Lactulose and lactose. Clin Chim Acta 187, $79-88$.

25. World Health Organisation (2001) Iron Deficiency Anaemia: Assessment, Prevention and Control. Geneva: WHO.

26. Lumanti Support Group for Shelter (2001) Situational Analysis of Urban Poor Communities in Kathmandu and Lalitpur. Kathmandu: Lumanti Support Group for Shelter.

27. Travis S \& Menzies I (1992) Intestinal permeability: functional assessment and significance. Clin Sci 82, 471-488. 